\title{
Preferences for coastal and marine conservation in Vietnam: Accounting for differences in individual choice set formation
}

\author{
Tobias Börger \\ Department of Business and Economics, Berlin School of Economics and Law, Germany \\ Economics Division, University of Stirling, UK \\ Email: tobias.boerger@hwr-berlin.de \\ Quach Thi Khanh Ngoc \\ Faculty of Economics, Nha Trang University, Vietnam \\ Laure Kuhfuss \\ James Hutton Institute, Dundee, UK \\ School of Geography and Sustainable Development, University of St Andrews, UK \\ Tang Thi Hien \\ Faculty of Economics, Nha Trang University, Vietnam

\section{Nick Hanley} \\ Institute of Biodiversity, Animal Health and Comparative Medicine, University of Glasgow, UK

\section{Danny Campbell} \\ Economics Division, University of Stirling, UK
}

\begin{abstract}
This paper has two objectives. The first is to estimate the value of implementing new coastal and marine conservation measures in Vietnam, focussing on the relative benefits of water quality improvements, coral conservation and control of marine plastic pollution. The second is to explicitly model any tendency of respondents to fail to give consideration to the "opt-out" or status quo option in a choice experiment, due to social and cultural factors. The analysis employs the independent availability logit model with random coefficients to simultaneously account for heterogeneity of preferences and choice set formation. Results show significantly improved model fit when consideration set heterogeneity is taken into account. However, estimates of preference weights and marginal willingness to pay for marine conservation measures are unaffected by this modelling choice.
\end{abstract}

Keywords: marine plastic pollution, status quo bias, choice experiments, independent availability logit, marine protected areas, Vietnam 


\section{Introduction}

Vietnam has 3,260km of coastline, facing the Gulf of Tonkin and the South China Sea in the east and the Gulf of Thailand in the west. Since 2002 the Vietnamese government has been building a network of marine protected areas as a major tool of environmental policy, in order to conserve biodiversity and improve coastal water quality. In addition to these more traditional policy targets, marine plastic pollution has recently gained interest as an additional major threat to the environmental sustainability of global seas. The seas in Southeast Asia have been shown to exhibit very high amounts of plastic litter: Jambeck et al. (2015) identify Vietnam as number four in the list of the world's highest emitters of plastics pollution into the ocean. Against this background, this study employs a discrete choice experiment (DCE) to assess the preferences of members of the Vietnamese public in the city of Nha Trang regarding different targets of environmental policy in the coastal zone. The study focuses on coastal water quality and conservation of corals as more 'traditional' coastal and marine policy objectives (Xuan et al. 2017); and measures to curb marine plastic pollution in coastal areas as an example of a new and emerging environmental policy focus. Valuation of plastic pollution is only just emerging, with relatively few studies exclusively in Europe (Abate et al. 2020, Brouwer et al. 2017, Latinopoulos et al. 2018), and so far no studies in low-income countries, which are often pollution hotspots. ${ }^{1}$ We are therefore interested in the relative values which citizens place on these different aspects of marine and coastal ecosystems in a low-income context.

On a methodological level, this study examines the role of endogenous choice set formation in stated choice models. In the data set collected in this survey study, about three quarters of respondents never chose the status quo option. This is despite extensive pretesting of the survey instrument. The analysis explores the possibility that respondents might feel compelled to answer stated choice questions in a way that puts them in a socially and politically positive light, causing them to ignore the do-nothing-more status quo, and focus instead solely on options which involve a change, even though this is costly. Such a tendency might arise because environmental protection and contributions to such measures are actions which are often governed by social and cultural norms. Such influences might affect how people choose in the survey interview. Conventional choice modelling techniques based on the random utility model (RUM) (McFadden 1974, Train 2009) assume that respondents take all presented options into consideration when stating their choice over a set of environmental management options. That is, it is typically assumed that respondents weigh up the

\footnotetext{
${ }^{1}$ The stated preference study by Schuhmann et al. (2016) included an attribute on beach litter without specifically referring to plastic.
} 
expected utility from each and all of the options presented before making their choice. However, in our data set, evidence shows that a substantial portion of respondents did not consider all options presented to them. In particular, attitudinal statements suggest that these respondents did not consider the no-change, no-cost option since they might have perceived a duty as citizens to contribute at least a small amount to the proposed environmental management project. Therefore, the study employs the independent availability logit (IAL) model (Campbell and Erdem 2018) with random coefficients to allow for the use of choice heuristics and so to estimate preference coefficients which are unbiased by potential choice consideration set heterogeneity, while still being able to explore preference heterogeneity across respondents.

This analysis is related to a recent interest in the environmental valuation literature in the exploration of choice set formation on the performance of random utility-based discrete choice models (Campbell et al. 2018, Li et al. 2015). A part of this literature has considered the role of attribute cut-offs in choice set formation (Campbell et al. 2014, Swait 2001). Another focus of such models has been on choices of visiting recreational (Thiene et al. 2017) or hunting sites (Truong et al. 2018) using revealed preference data. The basic idea of the study of choice set formation is to view choice as a two-step process. First, a respondent scans which options are on offer, deciding which subset to look at. This subset may be equal to or smaller than the full set of options available. Second, she finds her most preferred alternative from this subset. This type of analysis is rarely applied to stated choice data, where it is typically assumed that respondents consider all options presented to them in a choice task. Moreover, by specifying a class membership function in the IAL model, the analysis can identify types of respondents who consider only a subset of the choice options presented.

This analysis is particularly important against the background of the increased use of stated preference valuation in low-income countries. ${ }^{2}$ It may be that tendencies to consider only a subset of options being offered due to social desirability (Börger 2013), lack of empowerment, lack of experience with democratic consultative processes and acquiescence are more frequently encountered in low-income country settings. This possibility was suggested many years ago by Whittington (1998) in the context of contingent valuation.

The remainder of the paper is structured as follows. Section 2 reviews marine and coastal management as well as previous applications of stated preference valuation in Vietnam. Section 3 introduces the methodology; Section 4 presents the results, which are discussed in Section 5.

\footnotetext{
${ }^{2}$ These methods have increasingly been used in Europe and North America to value natural capital and support the design of coastal and marine policies (e.g. Börger et al. 2014, Brouwer et al. 2017, Norton and Hynes 2014, Stefanski and Shimshack 2016, Wattage et al. 2011).
} 


\section{Marine and coastal management and environmental valuation in Vietnam}

\subsection{Marine and coastal management in Vietnam}

Marine and coastal management in Vietnam has mainly focused on the implementation of integrated coastal zone management (ICZM). With a high concentration of people in coastal areas and ensuing intensive use of coastal resources, ICZM has become an effective framework for environmental management in Vietnam since its introduction in the 1990s (Cuong and Van Cu 2014). The main aim of the ICZM strategy in Vietnam is to ensure sustainable economic and social development by protecting coastal natural resources. ICZM facilitates better coordination between agencies in planning and implementation but still faces challenges, such as conflicts between stakeholders and an ineffective legislative framework supporting it (Nagothu 2005).

In the evolution of ICZM in Vietnam, the installation of marine protected areas (MPAs) has been recommended as the national strategy for biodiversity conservation in the coastal and marine environment. A network of 16 MPAs with a total area of 270,000 ha from north to south of the country has been approved for establishment so far (Ngoc 2018). At this point in time, 11 of those approved MPAs have also been established. The main objectives of these MPAs are to conserve biodiversity and to improve the livelihoods of local people. For the objective of biodiversity conservation, six target resources are protected including water quality, seagrass beds, coral reefs, mangroves, sea turtle populations and reef fish (Walton et al. 2015). However, the achievement of these conservation targets has been hampered by a lack of sustainable financing and regulatory enforcement (Walton et al. 2015).

Compared to the conservation objectives discussed above, the focus on marine plastics pollution in Vietnam is far more recent. Jambeck et al. (2015) estimate that for Vietnam between 280,000 and 730,000 tons of plastic waste enter the marine environment per year. This makes Vietnam the fourth largest global emitter of marine plastic waste and shows that plastic pollution has become a real and more serious environmental problem in Vietnam. Such pollution has diverse origins, as it is emitted from land (from landfill sites or unofficial waste dumps (Thang 2019)) and from marine activities, such as recreational and tourism, abandoned fishing gear and shipping waste. The Vietnamese government has acknowledged the seriousness of marine plastic pollution and recently made a big effort to deal with the problem. The "National Strategy on Integrated Management of Solid Waste to 2025, Vision to 2050 " sets a goal of using environmentally friendly plastic bags at stores and supermarkets by 2026 (Thang 2019). The government has developed an action plan to mitigate marine debris pollution that focuses on: 1) enhancing the management capacity and improve the policy-making mechanism 
regarding marine debris control; 2) enhancing the research capacity on the issue of marine debris including factual analysis, trends of marine debris pollution and its impacts on marine life and ecosystem in different perspectives; 3 ) increasing public awareness, among manufacturers, goods distributors, consumers and others about marine debris; and 4) strengthening international cooperation in knowledge and information sharing regarding transboundary issues of marine debris pollution.

The present valuation study focuses on Nha Trang Bay (NTB), a coastal area adjacent to the Vietnamese city of Nha Trang (population 500,000) located on the central southern coast (Figure 1). While up until the 1990s, the main economic sectors of Nha Trang city and its surrounding Khanh Hoa Province were forestry, agriculture and fishing, the tourism and industrial sectors have seen rapid recent development since. The area has seen growth in the number of infrastructure and other construction projects and Nha Trang has grown into a very popular destination for domestic and international tourists. Ports, roads, hotels and resorts have not only been built in mainland Nha Trang but also on some of the islands located in the Bay.

\section{Figure 1}

NTB has the largest level of marine biodiversity in Vietnamese coastal waters (Tuan et al. 2002), thereby acting as a biodiversity hotspot within the country and a priority site listed in the Vietnam Biodiversity Action Plan (MONRE 2015). The biodiversity is relatively high for the overall Indo-West Pacific Ocean (Tuan et al. 2005). This area also provides fish larvae to other Vietnamese waters and possibly to Cambodian waters (Wilkinson 2000). As a consequence of this ecological importance of the area, NTB hosts one of Vietnam's 11 MPAs, established in 2001 (Nam et al. 2005). The objectives for this MPA are the conservation of seafloor ecosystems such as coral reefs and seagrass and the maintenance and improvement of water quality. The protected area, however, only covers a small portion of the whole Bay. Coral reefs cover an area of 730 ha which amounts to $1.44 \%$ of the total Bay area $\left(507 \mathrm{~km}^{2}\right)$. At the moment, only $22.3 \%$ of the area suitable for coral growth was actually inhabited by living corals (Kimura et al. 2014).

It has been shown that coral reefs in NTB generate substantial values for the tourism industry (Nam et al. 2005, Xuan et al. 2017), yet it is unclear what value the protection of this ecosystem type generates for the local population. Therefore, the present study assesses the values held by the local population for: (i) improvement in coastal water quality; (ii) conservation of coral reefs; and (iii) measures to curb marine plastic pollution in coastal areas. 


\subsection{Stated preference design considerations in Vietnam}

Notwithstanding substantial reform efforts over the past 30 years, the political system of the Socialist Republic of Vietnam is markedly hierarchical (London 2014). While ongoing institutional reforms (including the environmental sector) have produced a larger and more complex network of actors in environmental policy-making, decision-making, including on proposals for environmental programmes, is reserved for government and implemented by governmental agencies (Ortmann 2017). In this process, the general public is not routinely consulted (Hostovsky et al. 2010). Consequently many people see the responsibility for environmental protection resting exclusively with the government (Phung 2007). More specifically, it has been found that in surveys asking for willingness to pay (WTP) for environmental protection respondents from low-income Asian societies, including Vietnam, show higher levels of acquiescence, i.e. the tendency to answer a survey question in the affirmative irrespective of its content (Franzen and Vogl 2013). Translated into a DCE setting, acquiescence could entail respondents who always state their support for the proposed environmental programme irrespective of the attribute levels displayed. This means that such respondents systematically avoid choosing the status quo option. In a more general sense, acquiescence bias can be conceptualised as an individual-specific limitation of the choice set. ${ }^{3}$

In a typical DCE offering a choice set consisting of a (no-cost) status quo and one or more change options (involving a cost to the respondent), support for the proposed environmental project can be expressed by stating a preference for any one of the change options. If a respondent, because of acquiescence or some other reason, feels compelled to express support for the proposed project regardless of its specifications, the no-cost status quo option effectively drops out of the consideration set. This might be an expression of acquiescence bias in the DCE context. Similarly, if a respondent objects to the environmental project or the survey method (out of ethical, political or other reasons), they might systematically ignore the (costly) change options and always only consider and choose the status quo. This has been referred to as serial non-participation (von Haefen et al. 2005, Meyerhoff and Liebe 2009). In this case, the set of options offered in the survey will differ from the individual consideration set relevant to each individual in the sample.

\footnotetext{
${ }^{3}$ It can be argued that a motivation to acquiesce is opposite to a motivation to provide a protest response to the choice or WTP question. Protest responses are rejections of the valuation scenario, which for the case of a choice experiment manifest in a consistent selection of the status quo option (Meyerhoff and Liebe 2008, 2009).
} 


\section{Methodology}

\subsection{Development of the survey instrument}

The survey instrument and valuation scenario was developed following recent guidelines on stated preference methods (Johnston et al. 2017). A draft questionnaire and valuation scenario was discussed in two focus group meetings with a total $N=15$ participants sampled from the general public. Subsequently, three pilot surveys each with $N=40$ respondents were conducted to test and refine the survey instrument and inform the experimental design for the main survey. Respondents of the pilot surveys were sampled from the same underlying population as the subsequent main survey. The first pilot employed a Bayesian experimental design with zero priors. Based on the responses from the each pilot survey, the estimated preference weights from a multinomial logit model (see next section) were used to generate a Bayesian D-efficient design for the main survey. This consists of a set of 12 choice sets separated into two blocks of six. In each choice set, a respondent is offered three options: the status quo option ("Current Status") and two potential change options ("Plan A", "Plan B").

The valuation scenario describes a publicly funded Nha Trang Bay Management Plan. To increase perceptions of consequentiality of their responses, survey participants were informed that a government consultation for the elements of such a plan was currently being undertaken and that this survey was part of that. Proposed activities within the Plan include improved treatment of municipal waste water, more stringent regulations for aquaculture operators, better protection of coral reefs, more frequent collection of plastic waste from beaches, and measures to reduce the use of plastic bags in the city. The main consequences of the potential implementation of these measures were then described as the choice attributes (Table 1).

The first attribute, water quality in NTB, is affected by the treatment of municipal waste water, aquaculture and tourism in the Bay and construction along the coast. Other sources of water pollution are run-off of fertilisers from the agricultural sector and from aquaculture sites. Different chemicals, such as arsenic and heavy metals along with coliform bacteria are washed into the sea. Respondents were informed that with the NTB Management Plan enacted, the concentration of these chemicals in the water would go down. Therefore, water quality would improve, which would also substantially enhance the clarity of the water in the nearshore areas. There are a number of studies valuing improvement of coastal water quality improvements for beach users (e.g. Beharry-Borg and Scapa 2010, Hynes et al. 2013, Peng and Oleson 2017), so in this sense this attribute represents a 'traditional' objective of coastal management. 
The second attribute concerns coral cover in the Bay. At the moment, only around $20 \%$ of the underwater reefs are covered by corals, and coral reefs are protected in areas around some of the islands in the Bay (Kimura et al. 2014). An increase in the area of NTB covered by corals is in line with Vietnam's national biodiversity strategy which calls for the restoration of $25 \%$ of degraded ecosystems by 2030 (MONRE 2015). Respondents were informed that if the Management Plan is implemented, coral reefs could be protected and expand to cover $30 \%$ or $50 \%$ of the underwater reef area. For this attribute, too, there have been in a number of valuation studies in other areas, such as Wielgus et al. (2003) and Peng and Oleson (2017).

\section{Table 1}

The third attribute focuses on the problem of increasing plastic pollution in NTB. While the base level was no additional action to tackle this problem, two types of measures were proposed to reduce marine plastic pollution. To prevent plastic waste reaching the coastal water and beach areas, one proposed option is to filter plastic out of small rivers and streams before they reach the Bay. This options also includes regular waste collection at the municipal beaches in the city centre. An alternative option presented in the survey is a reduction of the use of plastic bags in the city by banning their use for certain everyday purposes, e.g. in supermarkets and corner shops.

The cost attribute is described in terms of a water fee to be paid by all household in Nha Trang. Respondents were informed that in case the management plan is implemented, all households in Khanh Hoa Province would have to pay the amount as lump-sum addition to any existing water bill for five years. Households in Nha Trang routinely pay fees for waste collection and water. Therefore, linking the payment in the stated preference survey to an existing fee was regarded as most realistic payment vehicle in the focus groups. ${ }^{4}$ Different cost vectors were tested in the four pilot surveys as initially cost levels were viewed by most focus group participants as being too high for the target population. Consequently, cost levels were reduced successively in the piloting process. ${ }^{5}$ After initially specifying the fee to be paid annually, which respondents found unrealistic, a monthly fee was found to work better. It is worth stressing that the pilot surveys did not yield any indication that the cost vector was too low. On the contrary, it was perceived as high by most respondents. Figure 2 is the English translation of an example choice card. Information in the valuation scenario further included

\footnotetext{
${ }^{4}$ Householders in Nha Trang are used to this payment vehicle. For instance, households pay VND 44,000 per month for the regular household waste collection. This amount informed the selection of the maximum amount in the initial (yearly) price vector.

${ }^{5}$ The initial cost vector of yearly payments was $[0 ; 50,000 ; 100,000 ; 300,000 ; 500,000]$.
} 
a budget reminder and a reminder that public funds spent on management of NTB could not be used for other purposes, such as education and healthcare.

\section{Figure 2}

\subsection{Analysis of stated choice data}

The analysis of the stated choice data is based on the RUM (McFadden 1974). In this model, the utility respondent $n$ expects from option $i$ in choice situation $t$ can be expressed by a parameterised indirect utility function as

$$
V_{\text {nit }}=-\alpha_{n} C_{n i t}+\gamma_{n} X_{\text {nit }}+\epsilon_{\text {nit }} .
$$

$C_{n i t}$ is the cost of option $i$ in choice situation $t$, and $\gamma_{n}$ is the associated coefficient. $\gamma_{n}$ is a vector of preference weights, $X_{\text {nit }}$ is a vector containing the attribute levels (except cost) of choice option $i$ in situation $t . \epsilon_{\text {nit }}$ is an option-specific error term assumed to be independent and identically distributed following a Type I Extreme Value distribution. It is further assumed that the variance of that error term can differ across respondents and is specified as $\operatorname{Var}\left(\epsilon_{n i t}\right)=k_{n}^{2}\left(\pi^{2} / 6\right)$, with $k_{n}$ denoting the scale parameter specific to respondent $n$. Equation (1) can be divided by the scale parameter $k_{n}$ to yield

$$
V_{n i t}=-\lambda_{n} C_{n i t}+\beta_{n} X_{n i t}+\varepsilon_{n i t}
$$

where $\lambda_{n}=\alpha_{n} / k_{n}$ and $\beta_{n}=\gamma_{n} / k_{n}$. The model in WTP space (Train and Weeks 2005) is obtained by further substituting marginal WTP as $w_{n}=\beta_{n} / \lambda_{n}$, the ratio of the attribute's preference weight and the cost coefficient, such that

$$
V_{\text {nit }}=-\lambda_{n} C_{\text {nit }}+w_{n} \lambda_{n} X_{\text {nit }}+\varepsilon_{\text {nit }} .
$$

Note that $\varepsilon_{n i t}$ is an error term with variance $\pi^{2} / 6$ distributed Type I Extreme Value. In this model, the estimated elements of $w_{n}$ can be directly interpreted as marginal WTP for the respective attribute. Further assuming that respondent $n$ choses their utility-maximising option out of a choice set $j=$ $1, \ldots, J$ in any choice situation $t=1, \ldots, T_{n}$, the probability of recording a choice sequence $y_{n}=$ $\left[y_{n t}, \ldots, y_{n T}\right]$ is

$$
P\left(y_{n} \mid X_{n t}\right)=\prod_{t=1}^{T_{n}} \frac{\exp \left(-\lambda_{n} C_{n i t}+w_{n} \lambda_{n} X_{n i t}\right)}{\sum_{j=1}^{J} \exp \left(-\lambda_{n} C_{n j t}+w_{n} \lambda_{n} X_{n j t}\right)} .
$$


If it is assumed that $w_{n}=w$ we have the multinomial logit (MNL) model in WTP space. This model assumes that there is no heterogeneity in preferences (and WTP) for the choice attributes across respondents and only a vector of average WTP $(w)$ is estimated. One way of allowing inter-respondent preference (and WTP) heterogeneity is to assume for the elements of $w_{n}$ to be random variables, the mean and standard deviation of which can be estimated. This is the mixed logit (MXL) model (Revelt and Train 1998). It specifies $w_{n}=w+\eta_{n}$ where $\eta_{n}$ is a random variable representing a respondent specific deviation of the coefficient from the sample mean $w$. While different distributional assumptions can be made with respect to $\eta_{n}$, the analysis will assume $\eta_{n} \sim N\left(0, \sigma^{2}\right)$ for all but the cost coefficient with $\eta_{n} \sim L N\left(0, \sigma^{2}\right)$ for the coefficient of the cost attribute. The probability of a choice sequence in (4) is conditional on knowing $w_{n}$. Consequently, the unconditional choice probability is the expression in (4) weighted by the respective density function $f(w \mid \theta)$ :

$$
P\left(y_{n} \mid X_{n t}\right)=\int \prod_{t=1}^{T_{n}} \frac{\exp \left(-\lambda_{n} C_{n i t}+w_{n} \lambda_{n} X_{n i t}\right)}{\sum_{j=1}^{J} \exp \left(-\lambda_{n} C_{n j t}+w_{n} \lambda_{n} X_{n j t}\right)} f(w \mid \theta) d w
$$

where $\theta$ are the parameters of the assumed distributions of the elements of $w$.

The models introduced so far assume that every respondent considers all options $j$ in every choice situation $t$. However, it is conceivable that some respondents do not consider all options on offer: in a choice situation with three options $j \in\{1,2,3\}$ a respondent may, for example, systematically ignore the first option (e.g. the status quo), so that for this respondents in fact $j \in\{2,3\}$. Since the analyst cannot observe this choice behaviour (since no explicit information is recorded as to whether a respondent has or has not considered an unchosen option) a latent class framework can be used whereby a the probability of a respondent making a series of choices $y_{n}$ is conditional on belonging to a certain consideration set class $c=1, \ldots, C$ :

$$
P\left(y_{n} \mid X_{n t}, c\right)=\int \prod_{t=1}^{T_{n}} \frac{\exp \left(-\lambda_{n} C_{n i t}+w_{n} \lambda_{n} X_{n i t}\right)}{\sum_{j \in J_{c}} \exp \left(-\lambda_{n} C_{n j t}+w_{n} \lambda_{n} X_{n j t}\right)} f(w \mid \theta) d w
$$

In this expression, the consideration set $J_{c}$ is contingent on respondent $n$ belonging to class $c$. Note that the coefficients, $w_{n}$, are not class-specific, i.e. the classes only differ in the set of options a respondent considers when making their choice but not in terms of estimated WTP.

Since the analyst cannot observe the class that each respondent belongs to, a class membership function must be used to specify the probability of respondent $n$ belonging to any one consideration set class $c$ : 


$$
\pi\left(c \mid z_{n}\right)=\frac{\exp \left(\delta_{c} z_{n}\right)}{1+\sum_{l=1}^{C-1} \exp \left(\delta_{l} z_{n}\right)}
$$

where $z_{n}$ is a vector of respondent-specific variables (including a constant), and $\delta_{c}$ is a coefficient vector to be estimated. $\pi\left(c \mid z_{n}\right)$ is the probability that $J_{c}$ is the choice set that respondent $n$ actually considered, given a set of respondent-specific covariates $z_{n}$. The class membership function $\pi(\cdot)$ can then be used to express the unconditional probability of $y_{n}$ as

$$
P\left(y_{n} \mid X_{n t}\right)=\pi\left(c \mid z_{n}\right) \int \prod_{t=1}^{T_{n}} \frac{\exp \left(-\lambda_{n} C_{n i t}+w_{n} \lambda_{n} X_{n i t}\right)}{\sum_{j \in J_{c}} \exp \left(-\lambda_{n} C_{n j t}+w_{n} \lambda_{n} X_{n j t}\right)} f(w \mid \theta) d w,
$$

The analysis considers models with different numbers of classes of two (considering all options and ignoring the status quo) and three different choice heuristics (considering all options, ignoring the status quo, ignoring all change options). The specification of different consideration set classes in a latent class framework is known as the Independent Availability Logit (IAL) model (Campbell and Erdem 2018, Habib et al. 2013). Given the use of random coefficients in the indirect utility function, we will refer to these models as Independent Availability Mixed Logit (IA-MXL). The choice probability and class membership functions are jointly estimated using simulation due the inclusion of random coefficients in the choice equation. All above models are implemented using the Apollo syntax (Hess and Palma 2019a, b) in R (R Core Team 2017). All models involving random coefficients use 1,000 Sobol draws to simulate the likelihood. We used multiple sets of starting values in addition to the algorithm proposed by Bierlaire et al. (2010) to identify appropriate starting values increase the chances of convergence at a global log-likelihood maximum.

\section{Results}

\subsection{Sample characteristics}

The survey was conducted in September and October 2018 using in-person household interviews. Students at the Economics Department of Nha Trang University were trained as interviewers and conducted the survey across 17 of the 19 urban wards and 6 out of 8 suburban communes of Nha Trang city. Interviewers were sent to different wards and communes according to their relative population share and to different streets within wards. At these randomly allocated locations, respondents were then sampled while on the street, in open shops or in front of their houses. A sample of $N=422$ completed questionnaires was obtained. Sample characteristics are reported in Table 2. 
Of particular interest in Table 2 is the variable DUTY, which records the responses on a 5-point Likert agreement scale to the statement "I think it is my duty to contribute at least a small amount to the NTB management plan". 313 respondent ( $74.2 \%$ of the sample) either agree or strongly agree with the DUTY attitudinal statement. Further descriptive statistics of choice and attitudinal responses show that 319 respondents ( $75.6 \%$ of the sample) never chose the status quo alternative (Figure 2 ), whilst 22 respondents (5.2\% of the sample) chose the status quo option in all six choice occasions. There is substantial overlap of those respondents agreeing with the DUTY statement and never choosing the status quo option: 266 respondents (63\% of the sample) fall into this category. So agreement to the DUTY statement might indicate that a substantial portion of respondents did not actually consider the status quo as a viable response option. It is therefore likely that choice heuristics which reduce the consideration set affected the choices of a majority of respondents. The next section will look at a series of models, which successively take into account (1) preference heterogeneity and (2) heterogeneity of consideration sets across respondents.

\subsection{Preferences for coastal management objectives}

The left-hand side of Table 3 presents a MNL model as a baseline for analysis. On average, large improvements in water quality (WATER), coral cover (CORAL30 and CORAL50) as well as measures to address plastic pollution in coastal waters (WASTE_COLLECT and LIMIT_BAGS) affect choice probabilities positively. However, the coefficient of increasing coral cover to 50\% (CORAL50) is not significantly larger than that for an improvement to 30\% (CORAL30) (Wald-test: $p=.356$ ). The coefficient of the cost attribute is negative and significant. The coefficient of the alternative-specific constant (ASC) indicating the status quo option is negative and significant indicating that, on average, there is a strong preference for any type of the NTB Management Plan which is not explained by its other characteristics.

To explore potential preference heterogeneity an MXL model with correlated, normally distributed coefficients of the non-monetary attributes and a cost coefficient following a log-normal distribution was run (right-hand side of Table 3 ). ${ }^{6}$ Coefficient estimates by and large confirm the findings of the MNL model. The coefficient of improvement to $50 \%$ of coral cover (CORAL50) is again slightly larger than the one of CORAL30 in this model, but here too this difference is negligible. Respondents value a

\footnotetext{
${ }^{6}$ We also explored latent class and discrete mixture models to capture preference heterogeneity. However, latent class models were outperformed by mixed logit in terms of model fit, and discrete mixture models proved problematic due to the high number of parameters to estimate.
} 
moderate increase in coral cover from a baseline of $20 \%$ to $30 \%$ but are on average not willing to pay more for a further increase to $50 \%$. Estimates of the standard deviation of the random coefficients indicate the existence of substantial unexplained preference heterogeneity in the data. This heterogeneity will be explored in the subsequent section.

\section{Table 3}

The MXL model also yields a coefficient of the ASC which is several times larger than the other coefficient estimates. This indicates that considerations other than the level of the choice attributes might have led respondents to prefer any of the change options over the status quo. In such a situation where there might be a strong and unexplained dislike for any one of the options, an IAL type model might be more appropriate (Campbell and Erdem 2018).

Therefore, and to account for choice set formation, two types of IA-MXL models are explored. A first model with two consideration set classes (i. Consider all options ( $j \in\{1,2,3\}$ ); ii. Ignore status quo option $(j \in\{2,3\})$ and a second model with three such classes (i. Consider all options $(j \in\{1,2,3\})$; ii. Ignore status quo option ( $j \in\{2,3\})$; iii. Only consider status quo option [ $j=1]$ ). While both models exhibit better model fit than the MXL model in Table 3, the three-class IA-MXL model showed no improvement in model fit over the two-class model and also resulted in a class membership probability of Class iii of zero (estimates not reported here). We therefore conclude that two consideration set classes (i. Consider all options; ii. Ignore status quo option) sufficiently describe the choice processes prevalent in the data and will concentrate on this IA-MXL model specification in the following.

For the sake of completeness, Table 4 reports both IAL and IA-MXL models each with two consideration set classes. The IAL model in the left-hand side of the table is based on the MNL model and thus assumes homogenous preferences. Its fit to the data is markedly better than the MNL model in Table 3, yet attribute coefficients are virtually unchanged. Only the coefficient of the status quo option is now markedly positive indicating, on average, a strong preference for the status quo. Which is in direct contrast to the MNL and MXL models that assume the full consideration set. Note that this model predicts only $25 \%$ of respondents to be in Class $i$ in which respondents consider all three options. Among these respondents there is a strong preference for the status quo which the simple MNL model is unable to detect. In fact, the MNL model, by ignoring the fact that $75 \%$ of respondents might not have considered the status quo option, falsely identifies a strong preference for the proposed Nha Trang Bay Management Plan. 
Looking at the random coefficients version of this model, the IA-MXL model, we see that it also outperforms the standard MXL in Table 3 in terms of fit to the data (improvement of 11 log-likelihood units). A likelihood ratio test shows that this improvement in fit is significant $(p<.001)$, indicating that accounting for respondent-specific choice set formation better describes the choice processes than assuming $j \in\{1,2,3\}$ for all respondents. Comparing the IA-MXL to the standard MXL model, the coefficient of the status quo option (ASC) is substantially smaller and well in the range of the other mean estimates in the former model. The ASC coefficient has also switched sign and is now positive, although comparably small in magnitude. This shows that in the standard MXL model the ASC coefficient is inflated from the large share of respondents who never chose (and presumably not even considered) the status quo option. The IA-MXL model is able to deal with this choice behaviour and estimate mean coefficients which are unbiased by this type of behavioural heterogeneity of choice sets considered.

\section{Table 4}

The IA-MXL model further shows an expected class membership probability of Class i of 0.39 , i.e. only $39 \%$ of respondents are predicted to consider all three options when stating their choices. The remaining $61 \%$ of respondents are predicted to only consider the two change options (Options $A$ and B) and ignore the status quo completely.

Note that in the IA-MXL model the coefficient of CORAL50 is larger than the one of CORAL30 even though this difference is not significant. Respondents value a moderate increase in coral cover from a baseline of $20 \%$ to $30 \%$ but are on average not willing to pay for a further increase to $50 \%$. Further note that the reported coefficient of cost is effectively a confound of the underlying cost coefficient $\alpha_{n}$ and the scale parameter $k_{n}$. Therefore, the fact that the reported coefficient is insignificant does not mean that respondents are insensitive to cost. In this WTP-space model, coefficients of all nonmonetary attributes are significant, which means that marginal WTP estimates for these attributes are significantly different from zero.

Since the IA-MXL model operates with latent classes, it is possible to parameterise the class membership function and characterise respondents who are more or less likely to belong to a particular class. Outputs of these models are not reported here. However, such a model does not detect any effect of respondent gender, age, level of education, income and time spent in Nha Trang on the probability of being in either consideration set class. The variable DUTY, indicating strength of agreement with the statement "I think it is my duty to contribute at least a small amount to the NTB 
management plan", does not significantly influence class membership either. ${ }^{7}$ This shows that it would not have been possible to identify respondents who consider choice sets other than the full set without the use of the IA-MXL model and based on socio-demographic information alone.

\subsection{WTP for characteristics of coastal management policies in Nha Trang Bay}

Estimates of mean WTP for changes in the attribute levels can be extracted directly from the above WTP-space models. Note that the coefficients from the models in Tables 3 and 4 need to be scaled up by $100.95 \%$ confidence intervals of the means are computed using the estimated standard errors of the WTP space coefficients. Comparing WTP estimates across models, there is very little variation between model types. Accounting for choice set heterogeneity, i.e. moving from the MNL to the IAL or from the MXL to the IA-MXL model does not affect estimates of mean marginal WTP in this dataset. Estimates are also largely robust when comparing between models that ignore (MNL and IAL) and allow for random preference heterogeneity (MXL and IA-MXL). However, as a general tendency, estimates are slightly larger in the MXL and IA-MXL models.

\section{Table 5}

Comparing marginal WTP estimates across attributes we note that respondents have the highest WTP for measures addressing plastic pollution in the coastal zone (WASTE_COLLECT and LIMIT_BAGS). Out of these two measures, WTP for regular waste collection on the beaches is slightly higher, yet the difference is not significant. While marginal WTP for large improvements in water quality (WATER) is very similar as those for curbing plastic pollution, WTP for increases in coral cover in Nha Trang Bay, while still significant, are the smallest across all attributes. In particular, respondents are not willing to pay more for an increase of coral cover to $50 \%$ of all suitable reef areas from a current baseline of $20 \%$ (CORAL50) compared to an improvement to $30 \%$ cover (CORAL30).

The random-coefficient choice models in Table 4 show comparably large standard deviation estimates, which indicates a high degree of heterogeneity of preferences (and consequently WTP) across respondents. To further explore this heterogeneity we extract a panel of respondent-specific estimates of marginal WTP, each based on 1,000 draws from the coefficient's estimated distributions conditional on their choice sequence $y_{n}$ (Campbell 2007, Yao et al. 2014). Marginal WTP for attribute $k$ is directly obtained from these conditional draws since models were run in WTP space. Conditional

\footnotetext{
${ }^{7}$ Note that in the IAL model, DUTY is a significant covariate in the class membership function, with stronger agreement to the DUTY statement being associated with a higher probability of being in the class which ignores the status quo option $(j \in\{2,3\})$. These additional results are available from the authors on request.
} 
draws were taken based on estimates of the MXL and IA-MXL models. The resulting respondentspecific WTP estimates can be used in a random-effects ordinary least squares regression model to identify determinants of variation in WTP (Campbell 2007, Yao et al. 2014) according to

$$
W T P_{i k}=\alpha_{i}+\delta^{\prime} A_{k}+\vartheta^{\prime} Z_{i}+\mu_{i k}
$$

$W T P_{i k}$ denotes a 5-period panel of WTP estimates for respondent $i$ and attribute (level) $k$ (note that we do not include the WTP estimate for the status quo option - ASC). $\alpha_{i}$ is an independent random term; $A_{k}$ is an indicator vector of all but one attribute (levels) ${ }^{8} ; Z_{i}$ is a vector of respondent characteristics. $\delta$ and $\vartheta$ are coefficient vectors to be estimated. $\mu_{i k}$ is a normally distributed error term with mean zero.

Table 6 presents results of these models using conditional WTP estimates based on the MXL and IA-MXL models from Tables 3 and 4. Results show consistent effects across models. Male respondents (MALE), those with a university degree (UNI) and those who have spent all their life in Nha Trang (LIFE) tend to have higher WTP for the proposed attributes. The coefficient of household income (INCOME) is also positive and significant at the $5 \%$-level. The coefficient for respondent age is negative in both models but only significant at the $10 \%$-level in the model using WTP estimates based on the MXL model. The finding that the association of elicited WTP with these respondent characteristics is in line with expectations supports the validity of the stated preference responses.

\section{Table 6}

\section{Discussion and conclusions}

Most applications of stated preference choice modelling to environmental management problems assume that every respondent considers all options presented to them, weighing up the utility of choosing each before selecting their preferred option. In many such experiments, a do-nothing-more, pay-nothing-extra status quo is offered as one of the options in each choice set, since otherwise individuals are being forced to accept a costly change when in practice they may not vote for it; and since not offering such a status quo option greatly complicates the use of WTP estimates in costbenefit analysis. This study demonstrates the usefulness of the independent availability logit model in cases when there are indications that respondents have not considered the whole choice set before responding. The case examined is a choice experiment survey of coastal management policies in the city of Nha Trang, Vietnam. While we found that about three quarters of respondents consistently

\footnotetext{
${ }^{8}$ WATER is the omitted attribute and is therefore the reference category.
} 
rejected the do-nothing-more status quo option, the IA-MXL model further implies that almost two thirds of respondents do not even consider the status-quo option when completing the choice tasks. Results show a significantly improved fit to the data of models that take into account heterogeneity of choice consideration sets over standard (multinomial and mixed) logit models. The use of the IAMXL model further showed that no respondent only considers the status quo option. Additional analysis demonstrates that the identification of which respondents only consider a subset of the full menu of options is not possible based on socio-demographic or other obvious respondent characteristics alone; IA-MXL models with a set of socio-demographic variables in the class membership function show no effect of these socio-demographic respondent characteristics on the probability of being in either consideration set class. Therefore, we argue that the independent availability model (or a variant thereof) should be explored whenever there are indications that there is a portion of respondents who have not completed the choice tasks according to the RUM framework. Such choice behaviour constitutes a type of elimination-by-aspects choice heuristic (Campbell et al. 2014, Daniel et al. 2018). A number of causes of such choice behaviour have been suggested, such as lack of interest in the issue in question, complexity or sensitivity of the survey topic (Erdem et al. 2014). In the case of our study, the perception of a sense of duty towards the proposed public project was identified as a potential driver of ignoring the status quo option, which may well be related to the politico-cultural context in which the study was set. Future research needs to look into the prevalence of non-RUM choice heuristics and their underlying drivers.

The finding that moving from a standard MXL model to an IA-MXL specification, which takes into account heterogeneous choice set formation, affects only the magnitude of the status quo coefficient but leaves all other attribute coefficients virtually unchanged means that the decision of some respondents to ignore the status quo was independent of the attribute levels. This leaves estimates of marginal WTP unaffected in this application. In any case, this finding does not mean that ignoring choice set consideration would have negligible consequences for the use of welfare measures derived from stated preference choice modelling in cost-benefit analysis in other instances. The systematic ignoring of the status quo option constitutes a form of non-trading behaviour (Hess et al. 2010). As Hess et al. (2010) note, such response behaviour will mostly affect the alternative-specific constants, but might also impact the estimated preference weights and thereby WTP estimates too. In that case, failing to account for heterogeneity in choice set formation by means of independent availability type models might lead to biased preference and WTP estimates.

Heterogeneity in choice set formation has so far rarely been studied in the context of stated preference methods. However, as demonstrated by the analysis above, there may well be situations in which this modelling approach is beneficial and may help to uncover, and deal with, choice 
behaviour which is inconsistent with the standard RUM framework. We speculate that such situations are more likely to be encountered in countries where democratic approaches to environmental management (the participation of citizens in approving policy options, expressed through opinion polls, cost-benefit analysis or voting) are uncommon and consequently higher levels of acquiescence can be expected (Franzen and Vogl 2013).

While it is easy to establish the share of respondents who never chose a specific option (e.g. the status quo), this does not necessarily mean that they never considered the attribute levels of that option. So this inspection of the data can only be a first step which needs to be followed up by a careful application of a model that makes choice set formation endogenous, such as the IA-MXL model. In fact, although $75 \%$ of respondents never chose the status quo option, the IA-MXL model predicts that, in addition to never choosing it, just $61 \%$ were likely to never even having considered it. Whilst it is possible that this lack of consideration was due to the cost vector being too low, experience from the focus groups and during pilot surveying indicated that this was in fact not the case, with respondents stating that they felt the prices offered to be too high, rather than too low. In addition, only the status quo option came at zero cost, so that none of the improvement options was available a zero cost. Furthermore, looking at the acceptance rates of different cost levels shows that respondents were sufficiently sensitive to cost. The highest cost amount (VND25,000) was accepted in $32.6 \%$ of the choices when it was available. These values are $48.6 \% ; 53.0 \%$ and $57.8 \%$ for VND15,000; VND10,000 and VND5,000, respectively. These figures provide further evidence that the cost vector was sufficiently high for the choices to represent a real trade-off for respondents.

This study also adds to a small but growing number of studies valuing environmental improvement in Vietnam (e.g. Pham et al. 2018, Quynh et al. 2018, Xuan et al. 2017). The analysis demonstrates that the population of Nha Trang values a number of environmental improvements in the coastal zone. In terms of marine plastic pollution, this study is the first to our knowledge to elicit public preferences for measures to combat this type of pollution in Asia. Stated preference studies with marine plastic pollution related attributes have so far only been conducted in Europe (Abate et al. 2020, Brouwer et al. 2017, Latinopoulos et al. 2018). As such, this study provides guidance towards the development of integrated coastal management policies encompassing multiple policy objectives. While not the only way of assessing values for environmental improvements, and notwithstanding a number of methodological challenges, stated preference methods are able to capture non-use values and evaluate future, not yet implemented environmental policies (Hanley and Czajkowski 2019). Particularly in the face of a new and emerging policy objective, such as the reduction of marine plastic pollution, this approach therefore offers a way to assess the relative preference of the general public for different objectives. Independent of model specification, respondents place the highest average 
WTP on regular plastic waste collection at beaches, which is followed by their WTP for measures to limit the use of plastic bags in the city and thereby prevent the littering of estuaries and beaches. WTP for improvements in water quality fall into the same ballpark, however, WTP for coral conservation are substantially lower. This means that respondents appreciate dealing with the comparably 'new' environmental issue of plastic pollution substantially more than tackling a more traditional concern like the conservation of coral reefs.

\section{Acknowledgements}

This study was partly funded by a British Academy Newton Mobility Grant (NMGR1180407) and the Norwegian Agency for Development Cooperation (NORAD), NORHED Project SRV-13/0010.

\section{References}

Abate, T.G., Börger, T., Aanesen, M., Falk-Andersson, J., Wyles, K.J. and Beaumont, N. (2020) Valuation of marine plastic pollution in the European Arctic: Applying an integrated choice and latent variable model to contingent valuation. Ecological Economics 169, 106521.

Beharry-Borg, N. and Scarpa, R. (2010) Valuing quality changes in Caribbean coastal waters for heterogeneous beach visitors. Ecological Economics 69(5), 1124-1139.

Bierlaire, M., Thémans, M. and Zufferey, N. (2010) A heuristic for nonlinear global optimization. INFORMS Journal on Computing 22(1), 59-70.

Börger, T. (2013) Keeping up appearances: Motivations for socially desirable responding in contingent valuation interviews. Ecological Economics 87(0), 155-165.

Börger, T., Hattam, C., Burdon, D., Atkins, J.P. and Austen, M.C. (2014) Valuing conservation benefits of an offshore marine protected area. Ecological Economics 108(0), 229-241.

Brouwer, R., Hadzhiyska, D., loakeimidis, C. and Ouderdorp, H. (2017) The social costs of marine litter along European coasts. Ocean \& Coastal Management 138(Supplement C), 38-49.

Campbell, D. (2007) Willingness to Pay for Rural Landscape Improvements: Combining Mixed Logit and Random-Effects Models. Journal of Agricultural Economics 58(3), 467-483.

Campbell, D. and Erdem, S. (2018) Including Opt-Out Options in Discrete Choice Experiments: Issues to Consider. The Patient - Patient-Centered Outcomes Research.

Campbell, D., Hensher, D.A. and Scarpa, R. (2014) Bounding WTP distributions to reflect the 'actual' consideration set. Journal of Choice Modelling 11, 4-15. 
Campbell, D., Mørkbak, M.R. and Olsen, S.B. (2018) The link between response time and preference, variance and processing heterogeneity in stated choice experiments. Journal of Environmental Economics and Management 88, 18-34.

Cuong, N.Q. and Van Cu, N. (2014) Integrated Coastal Management in Vietnam: Current Situation and Orientation. Vietnam Journal of Marine Science and Technology 14(1), 89-96.

Czajkowski, M., Vossler, C.A., Budziński, W., Wiśniewska, A. and Zawojska, E. (2017) Addressing empirical challenges related to the incentive compatibility of stated preferences methods. Journal of Economic Behavior \& Organization 142(Supplement C), 47-63.

Daniel, A.M., Persson, L. and Sandorf, E.D. (2018) Accounting for elimination-by-aspects strategies and demand management in electricity contract choice. Energy Economics 73, 80-90.

Erdem, S., Campbell, D. and Thompson, C. (2014) Elimination and selection by aspects in health choice experiments: Prioritising health service innovations. Journal of Health Economics 38, 10-22.

Franzen, A. and VogI, D. (2013) Acquiescence and the Willingness to Pay for Environmental Protection: A Comparison of the ISSP, WVS, and EVS*. Social Science Quarterly 94(3), 637-659.

Habib, K.N., Morency, C., Trépanier, M. and Salem, S. (2013) Application of an independent availability logit model (IAL) for route choice modelling: Considering bridge choice as a key determinant of selected routes for commuting in Montreal. Journal of Choice Modelling 9, 14-26.

Hanley, N. and Czajkowski, M. (2019) The Role of Stated Preference Valuation Methods in Understanding Choices and Informing Policy. Review of Environmental Economics and Policy 13(2), 248-266.

Hess, S. and Palma, D. (2019a) Apollo version 0.0.8, user manual, www.ApolloChoiceModelling.com.

Hess, S. and Palma, D. (2019b) Apollo: a flexible, powerful and customisable freeware package for choice model estimation and application. Journal of Choice Modelling, 100170.

Hess, S., Rose, J.M. and Polak, J. (2010) Non-trading, lexicographic and inconsistent behaviour in stated choice data. Transportation Research Part D: Transport and Environment 15(7), 405-417.

Hostovsky, C., MacLaren, V. and McGrath, G. (2010) The role of public involvement in environmental impact assessment in Vietnam: towards a more culturally sensitive approach. Journal of Environmental Planning and Management 53(3), 405-425.

Hynes, S., Tinch, D. and Hanley, N. (2013) Valuing improvements to coastal waters using choice experiments: An application to revisions of the EU Bathing Waters Directive. Marine Policy 40(0), 137-144.

Kimura, T., Tun, K. and Chou, L.M. (2014) Status of coral reefs in East Asian Seas region: 2014, Global Coral Reef Monitoring Network. Ministry of the Environment. Government of Japan. 
Latinopoulos, D., Mentis, C., and Bithas, K. (2018) The impact of a public information campaign on preferences for marine environmental protection. The case of plastic waste. Marine Pollution Bulletin 131, 151-162.

Li, L., Adamowicz, W. and Swait, J. (2015) The effect of choice set misspecification on welfare measures in random utility models. Resource and Energy Economics 42, 71-92.

London, J. (2014) Politics in contemporary Vietnam: Party, state, and authority relations, Springer.

McFadden, D. (1974) Conditional logit analysis of qualitative choice behavior. In: Zarembka, P. (ed) Frontiers in econometrics, economic theory and mathematical economics., pp. 105-142, Academic Press, New York.

Meyerhoff, J. and Liebe, U. (2008) Do protest responses to a contingent valuation question and a choice experiment differ? Environmental and Resource Economics 39(4), 433-446.

Meyerhoff, J. and Liebe, U. (2009) Status quo effect in choice experiments: empirical evidence on attitudes and choice task complexity. Land Economics 85(3), 515-528.

MONRE (2015) Vietnam National Biodiversity Strategy to 2020, Vision to 2030. Ministry of Natural Resources and Environment, Ha Noi. https://www.cbd.int/doc/world/vn/vn-nbsap-v3-en.pdf

Nagothu, U.S. (2005) Integrated coastal zone management in Vietnam: Present potentials and future challenges. Ocean \& Coastal Management 48(9-10), 813-827.

Nam, P.K., Vo, T., Son, H., Cesar, H. and Pollnac, R. (2005) Financial sustainability of the Hon Mun Marine Protected Area. Lessons for other marine parks in Vietnam, Institute for Environmental Studies Free University Amsterdam.

Ngoc, Q.T.K. (2018) Impacts on the ecosystem and human well-being of the marine protected area in Cu Lao Cham, Vietnam. Marine Policy 90, 174-183.

Norton, D. and Hynes, S. (2014) Valuing the non-market benefits arising from the implementation of the EU Marine Strategy Framework Directive. Ecosystem Services 10(0), 84-96.

Ortmann, S. (2017) Environmental governance in Vietnam. Institutional reforms and failures, Plagrave MacMillan, Cham.

Peng, M. and Oleson, K.L. (2017) Beach recreationalists' willingness to pay and economic implications of coastal water quality problems in Hawaii. Ecological Economics 136, 41-52.

Pham, T.D., Kaida, N., Yoshino, K., Nguyen, X.H., Nguyen, H.T. and Bui, D.T. (2018) Willingness to pay for mangrove restoration in the context of climate change in the Cat Ba biosphere reserve, Vietnam. Ocean \& Coastal Management 163, 269-277. 
Phung, T.P. (2007) Community Involvement in Urban Watershed Management:From the US Pacific Northwest to Ho Chi Minh City, Vietnam. The Journal of Environment \& Development 16(3), 307327.

Quynh, C.N.T., Schilizzi, S., Hailu, A. and Iftekhar, S. (2018) Fishers' Preference Heterogeneity and Trade-offs Between Design Options for More Effective Monitoring of Fisheries. Ecological Economics 151, 22-33.

R Core Team (2017) A language and environment for statistical computing, Vienna, Austria.

Revelt, D. and Train, K. (1998) Mixed Logit with Repeated Choices: Households' Choices of Appliance Efficiency Level. Review of Economics and Statistics 80(4), 647-657.

Schuhmann, P.W., Bass, B.E., Casey, J.F. and Gill, D.A. (2016) Visitor preferences and willingness to pay for coastal attributes in Barbados. Ocean \& Coastal Management 134, 240-250.

Stefanski, S.F. and Shimshack, J.P. (2016) Valuing marine biodiversity in the Gulf of Mexico: Evidence from the proposed boundary expansion of the Flower Garden Banks National Marine Sanctuary. Marine Resource Economics 31(2), 211-232.

Swait, J. (2001) A non-compensatory choice model incorporating attribute cutoffs. Transportation Research Part B: Methodological 35(10), 903-928.

Thang, L.D. (2019) Overview of marine plastic debris in Vietnam in relation to international context, FIG Working Week 2019 Geospatial information for a smarter life and environmental resilience. Hanoi, Vietnam, April 22-26.

Thiene, M., Swait, J. and Scarpa, R. (2017) Choice set formation for outdoor destinations: The role of motivations and preference discrimination in site selection for the management of public expenditures on protected areas. Journal of Environmental Economics and Management 81(Supplement C), 152-173.

Train, K.E. (2009) Discrete choice models with simulation, Cambridge, Cambridge.

Train, K. and Weeks, M. (2005) Discrete choice models in preference space and willingness-to-pay space. In: Scarpa, R. and Alberini, A. (eds.) Application of simulation methods in environmental and resource economics, Dordrecht, 1-16.

Truong, T., Adamowicz, W. and Boxall, P.C. (2018) Modelling the Effect of Chronic Wasting Disease on Recreational Hunting Site Choice Preferences and Choice Set Formation over Time. Environmental and Resource Economics 70(1), 271-295.

Tuan, V.S., DeVantier, L.M., Long, N.V., Tuyen, H.T. and Hoa, N.X. (2002) Marine and Coastal Habitats of Hon Mun Marine Protected Area. Vietnam Baseline Survey, Nha Trang Bay. March-April 2002. Hon Mun Marine Protected Area Pilot Project Biodiversity Technical Report No. 5. 
Tuan, V.S., Long, N.V., Tuyen, H.T., Hoa, N.X. and De Vantier, L.M. (2005) Marine and Coastal Habitats of Nha Trang Bay Marine Protected Area, Khanh Hoa, Viet Nam: Reassessment 2002-2005. Hon Mun MPA pilot project. Biodiversity report No. 13.

von Haefen, R.H., Massey, D.M. and Adamowicz, W.L. (2005) Serial Nonparticipation in Repeated Discrete Choice Models. American Journal of Agricultural Economics 87(4), 1061-1076.

Walton, A., Hang, T.M., Hien, B.T.T., Duong, K.T., Hien, N.B., Bac, P.V. and Brunner, J. (2015) Vietnam Marine Protected Area - Management Effectiveness Evaluation, Gland, Switzerland: IUCN, 86pp.

Wattage, P., Glenn, H., Mardle, S., Van Rensburg, T., Grehan, A. and Foley, N. (2011) Economic value of conserving deep-sea corals in Irish waters: A choice experiment study on marine protected areas. Fisheries Research 107(1-3), 59-67.

Whittington, D. (1998) Administering contingent valuation questions in developing countries. World Development 26(1) 21-30.

Wielgus, J., Chadwick-Furman, N.E., Zeitouni, N. and Shechter, M. (2003) Effects of coral reef attribute damage on recreational welfare. Marine Resource Economics 18, 225-237.

Wilkinson C. (2000) Appraising a proposal on Hon Mun Marine Protected Area pilot project. Australian Marine Science Institute. Documents and appendix of Hon Mun MPA pilot project. Ha Noi, Vietnam, March 2000.

Xuan, B.B., Sandorf, E.D. and Aanesen, M. (2017) Informing management strategies for a reserve: Results from a discrete choice experiment survey. Ocean \& Coastal Management 145(Supplement C), 35-43.

Yao, R.T., Scarpa, R., Turner, J.A., Barnard, T.D., Rose, J.M., Palma, J.H.N. and Harrison, D.R. (2014) Valuing biodiversity enhancement in New Zealand's planted forests: Socioeconomic and spatial determinants of willingness-to-pay. Ecological Economics 98(0), 90-101. 
Figure 1: Location of Nha Trang city and Nha Trang Bay

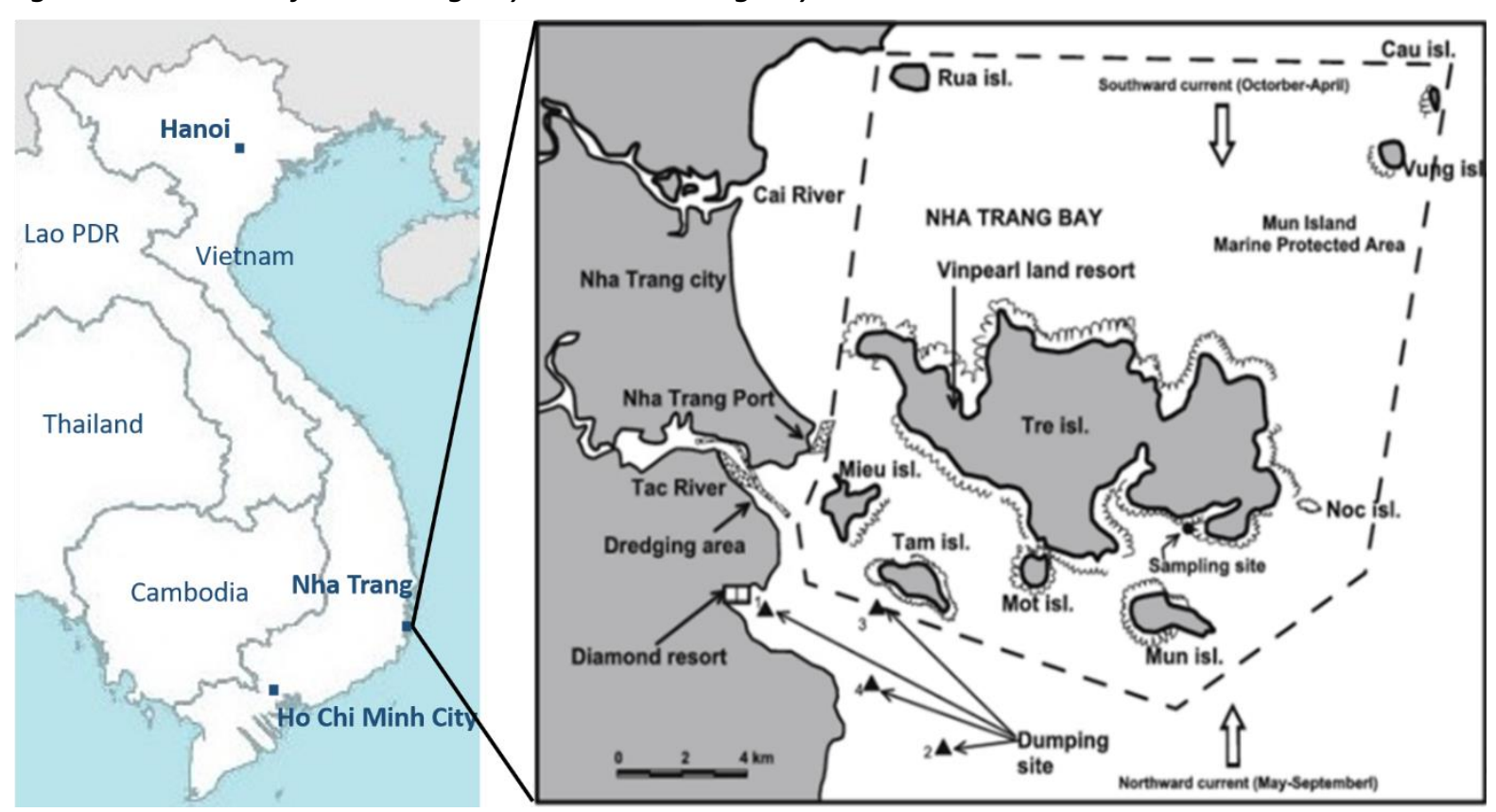


Figure 2: Example choice card

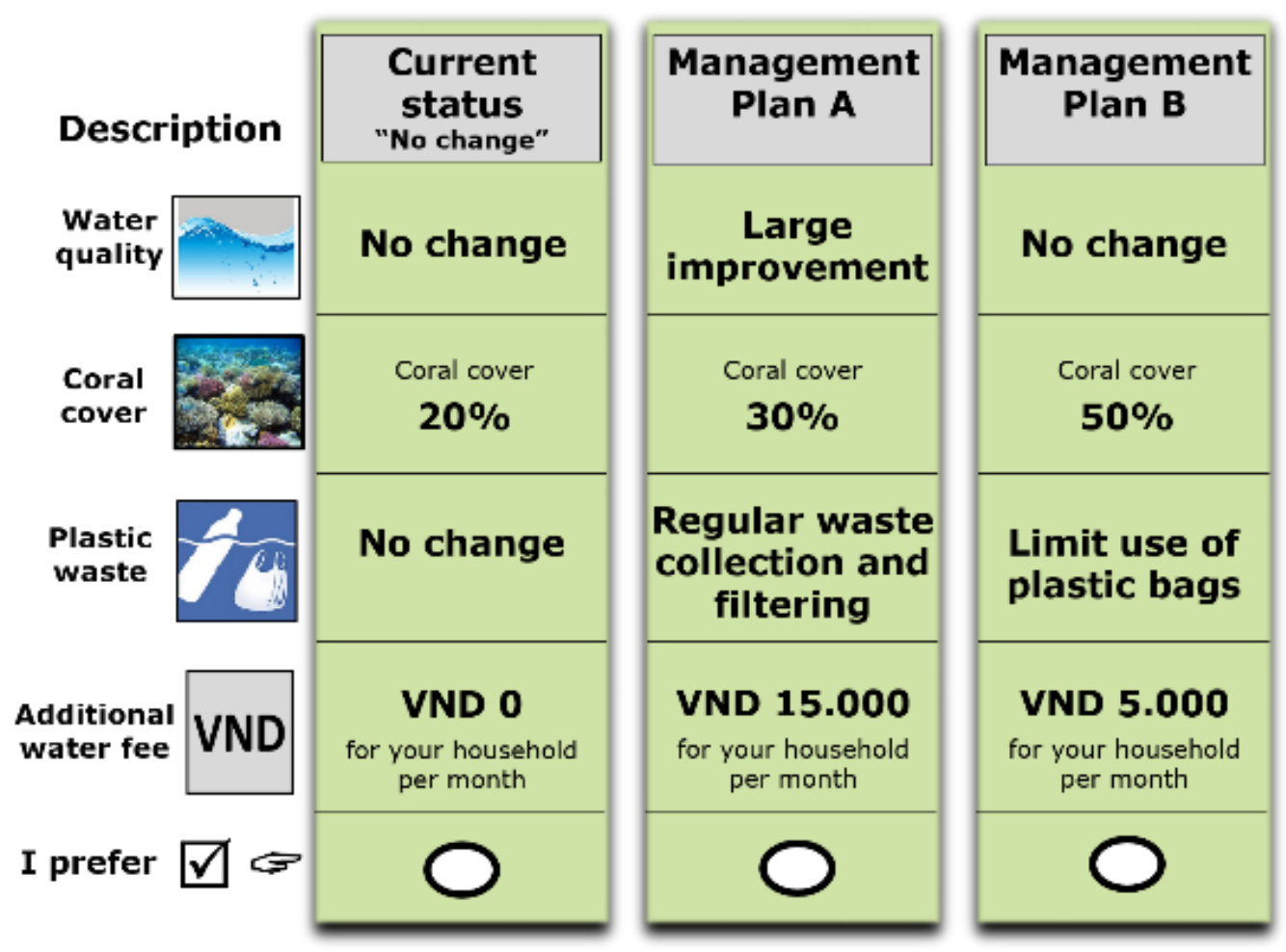


Table 1: Choice attributes and levels

\begin{tabular}{|c|c|c|}
\hline Attribute & Description & Levels \\
\hline Water quality & $\begin{array}{l}\text { Water quality in Nha Trang Bay is affected a many factors, such as } \\
\text { treatment of municipal waste water, aquaculture and tourism in the Bay, } \\
\text { construction along the coast. Different chemicals, such as arsenic and heavy } \\
\text { metals, and coliform bacteria are washed into the sea. If the activities } \\
\text { described above are implemented, the concentration of these chemicals in } \\
\text { the water would go down. Water quality and water clarity could improve. }\end{array}$ & $\begin{array}{l}\text { No } \\
\text { improvement; } \\
\text { large } \\
\text { improvement }\end{array}$ \\
\hline Coral cover & $\begin{array}{l}\text { Coral reefs can be found in Nha Trang Bay. At the moment, } 20 \% \text { of the } \\
\text { underwater reefs are covered by corals. At the moment, coral reefs are } \\
\text { protected in an area around Mun Island. If the above measures are } \\
\text { implemented, coral reefs could be protected even outside of that area. The } \\
\text { total cover of reefs by corals would increase. }\end{array}$ & $\begin{array}{l}20 \% ; 30 \% ; 50 \% \\
\text { of reefs covered } \\
\text { by live corals }\end{array}$ \\
\hline Plastic waste & $\begin{array}{l}\text { Plastic waste can be found all around Nha Trang Bay, on the beaches in Nha } \\
\text { Trang and on the islands, and in the open water. This plastic has many } \\
\text { sources which are hard to control, but it can be filtered out of small rivers } \\
\text { and streams before it reaches the Bay. It is also possible to collect plastic } \\
\text { waste from the beaches more regularly and to reduce the use of plastic bags } \\
\text { in the city. }\end{array}$ & $\begin{array}{l}\text { No change; } \\
\text { regular waste } \\
\text { collection and } \\
\text { filtering; reduce } \\
\text { the use of plastic } \\
\text { bags in the city }\end{array}$ \\
\hline Water fee & $\begin{array}{l}\text { Implementing these plans to manage the water and the marine } \\
\text { environment in Nha Trang Bay will be costly. The government therefore } \\
\text { needs to raise funds through an additional water fee. This fee is payable as } \\
\text { an addition to the monthly water bill by all households in Khanh Hoa } \\
\text { Province for the next } 5 \text { years. If the overall funds people are willing to } \\
\text { contribute do not cover the cost of implementing the plan, it cannot be put } \\
\text { into action. }\end{array}$ & $\begin{array}{l}0 ; 5,000 ; 10,000 ; \\
15,000 ; 25,000\end{array}$ \\
\hline
\end{tabular}

Notes: Status quo in italics 
Table 2: Sample characteristics

\begin{tabular}{llrrrrr}
\hline \multicolumn{1}{c}{ Variable } & \multicolumn{1}{c}{ Unit } & Mean & Std. dev. & Min. & Max. & \multicolumn{2}{c}{ Population } \\
\hline \hline MALE & Share & 0.47 & 0.50 & 0 & 1 & $48.50^{\mathrm{d}}$ \\
AGE & Years & 37.87 & 13.05 & 18 & 79 & $31.00^{\mathrm{e}}$ \\
UNI $^{\mathrm{a}}$ & Share & 0.43 & 0.50 & 0 & 1 & $37.28^{\mathrm{f}}$ \\
LIFE $^{\mathrm{b}}$ & Share & 0.44 & 0.50 & 0 & 1 & - \\
INCOME $^{\mathrm{c}}$ & million VND & 6.22 & 3.32 & 1 & 12 & $6.33^{\mathrm{d}}$ \\
HHSIZE & People & 4.63 & 1.61 & 1 & 14 & - \\
DUTY & 1-5 Likert scale & 3.76 & 0.72 & 1 & 5 & - \\
\hline
\end{tabular}

Notes: $\mathrm{N}=422$.

${ }^{a}$ Respondents with at least a university degree.

${ }^{b}$ Respondents who have lived their whole life in Nha Trang.

$c$ based on midpoints of income brackets.

d Figure for the provincial level: Khanh Hoa Province Department of Statistics

e Figure for the national level. Source: General Statistics Office of Vietnam

${ }^{f}$ Figure for the national level. Source: Department of Labor, War Invalids and Social Affairs 
Table 3: Multinomial and mixed logit models

\begin{tabular}{|c|c|c|c|c|c|c|}
\hline & \multicolumn{2}{|l|}{ MNL } & \multicolumn{4}{|c|}{$M X L^{a}$} \\
\hline & \multirow[b]{2}{*}{ Coef. } & \multirow[b]{2}{*}{ s.e. } & \multicolumn{2}{|l|}{ Means } & \multicolumn{2}{|c|}{ Standard Deviations } \\
\hline & & & Coef. & s.e. & Coef. & s.e. \\
\hline ASC & $-0.278 * * *$ & $(0.042)$ & $-0.480 * * *$ & $(0.013)$ & $0.563 * * *$ & $(0.016)$ \\
\hline WATER & $0.091 * * *$ & (0.019) & $0.111 * * *$ & $(0.005)$ & $0.170 * * *$ & $(0.005)$ \\
\hline CORAL30 & $0.081 * * *$ & $(0.014)$ & $0.076 * * *$ & $(0.007)$ & $0.162 * * *$ & $(0.005)$ \\
\hline CORAL50 & $0.064 * * *$ & $(0.024)$ & $0.064 * * *$ & $(0.013)$ & $0.555 * * *$ & $(0.017)$ \\
\hline WASTE_COLLECT & $0.101 * * *$ & $(0.022)$ & $0.159 * * *$ & $(0.017)$ & $0.382 * * *$ & $(0.017)$ \\
\hline LIMIT_BAGS & $0.090 * * *$ & (0.019) & $0.137 * * *$ & $(0.010)$ & $0.207 * * *$ & $(0.007)$ \\
\hline COST & $-4.142 * * *$ & $(0.399)$ & $4.135 * * *$ & $(0.274)$ & $2.295 * * *$ & $(0.237)$ \\
\hline Log-likelihood & $-2,395$ & & $-1,666$ & & & \\
\hline Adjusted $\rho^{2}$ & 0.136 & & 0.388 & & & \\
\hline $\mathrm{BIC}$ & 4,846 & & 3,607 & & & \\
\hline Parameters & 7 & & 35 & & & \\
\hline
\end{tabular}


Table 4: Independent availability (IAL) and independent availability mixed logit (IA-MXL) models

\begin{tabular}{lcccccc}
\hline & \multicolumn{2}{c}{ IAL } & \multicolumn{3}{c}{ IA-MXL } \\
& Coef. & s.e. & Means & \multicolumn{2}{c}{ Standard Deviations } \\
& $0.197^{* * *}$ & $(0.045)$ & $0.013^{* * *}$ & $(0.001)$ & $0.102^{* * *}$ & $(0.002)$ \\
\hline \hline ASC & $0.092^{* * *}$ & $(0.018)$ & $0.120^{* * *}$ & $(0.003)$ & $0.185^{* * *}$ & $(0.018)$ \\
WATER & $0.081^{* * *}$ & $(0.013)$ & $0.074^{* * *}$ & $(0.005)$ & $0.131^{* * *}$ & $(0.001)$ \\
CORAL30 & $0.070^{* * *}$ & $(0.023)$ & $0.095^{* * *}$ & $(0.003)$ & $0.542^{* * *}$ & $(0.001)$ \\
CORAL50 & $0.114^{* * *}$ & $(0.023)$ & $0.134^{* * *}$ & $(0.013)$ & $0.380^{* * *}$ & $(0.044)$ \\
WASTE_COLLECT & $0.097^{* * *}$ & $(0.019)$ & $0.116^{* * *}$ & $(0.009)$ & $0.176^{* * *}$ & $(0.002)$ \\
LIMIT_BAGS & $-4.302^{* * *}$ & $(0.416)$ & 7.193 & $(4.769)$ & 5.685 & $(4.279)$ \\
COST & & & & & &
\end{tabular}

Class membership probabilities

Class i (Consider all options) $\quad 0.25 \quad 0.39$

Class ii (Ignore SQ option) $\quad 0.75 \quad 0.61$

\begin{tabular}{lrr}
\hline Log-likelihood & $-2,118$ & $-1,655$ \\
Adjusted $\rho^{2}$ & 0.236 & 0.392 \\
BIC & 4,300 & 3,593
\end{tabular}

Parameters $\quad 8$

Notes: 2,532 choice occasions over 422 respondents. ${ }^{* * *}$ indicates significance at the $1 \%$-level of confidence. We use robust standard errors.

a Likelihood simulated using 1,000 Sobol draws. All but the cost coefficient are assumed to follow a normal distribution. The cost coefficient follows a lognormal distribution with sign reverse. All random coefficients are correlated. 
Table 5: Estimates of mean marginal WTP based on models in Tables 3 and 4

\begin{tabular}{lcccc}
\hline & MNL & IAL & MXL & IA-MXL \\
\hline \hline \multirow{2}{*}{ WATER } & 9.08 & 9.21 & 11.08 & 11.97 \\
& {$[5.40-12.77]$} & {$[5.61-12.82]$} & {$[10.02-12.14]$} & {$[11.37-12.57]$} \\
CORAL30 & 8.12 & 8.11 & 7.57 & 7.37 \\
& {$[5.45-10.79]$} & {$[5.49-10.74]$} & {$[6.16-8.99]$} & {$[6.48-8.25]$} \\
CORAL50 & 6.41 & 6.97 & 6.38 & 9.48 \\
& {$[1.80-11.02]$} & {$[2.39-11.54]$} & {$[3.89-8.87]$} & {$[8.98-9.98]$} \\
WASTE_COLLECT & 10.06 & 11.36 & 15.91 & 13.44 \\
& {$[5.78-14.35]$} & {$[6.79-15.93]$} & {$[12.54-19.28]$} & {$[10.95-15.93]$} \\
LIMIT_BAGS & 8.97 & 9.68 & 13.66 & 11.62 \\
& {$[5.33-12.62]$} & {$[5.93-13.44]$} & {$[11.78-15.55]$} & {$[9.80-13.43]$} \\
\hline
\end{tabular}

Notes: WTP in VND 1,000, which is equivalent to GBP0.034. 95\% confidence intervals in parentheses. 
Table 6: Random-effects ordinary least squares (OLS) regression of individual-specific WTP estimates

\begin{tabular}{|c|c|c|c|c|}
\hline & \multicolumn{2}{|c|}{ OLS (based on MXL) } & \multicolumn{2}{|c|}{ OLS (based on IA-MXL) } \\
\hline & Coef. & s.e. & Coef. & s.e. \\
\hline CONSTANT & 0.004 & (0.048) & 0.035 & $(0.048)$ \\
\hline \multicolumn{5}{|c|}{ Attribute (ref: WATER) } \\
\hline CORAL30 & $-0.038 * * *$ & $(0.010)$ & $-0.045 * * *$ & $(0.008)$ \\
\hline CORAL50 & $-0.047^{*}$ & $(0.025)$ & -0.021 & $(0.023)$ \\
\hline WASTE_COLLECT & $0.043 * *$ & $(0.018)$ & 0.014 & $(0.016)$ \\
\hline LIMIT_BAGS & 0.017 & $(0.012)$ & -0.004 & $(0.009)$ \\
\hline MALE & $0.034 *$ & (0.019) & $0.031 *$ & $(0.018)$ \\
\hline AGE & -0.001 & (0.001) & $-0.001 *$ & (0.001) \\
\hline UNI & $0.046 * *$ & $(0.020)$ & $0.047^{* *}$ & $(0.020)$ \\
\hline INCOME & $0.006^{* *}$ & $(0.003)$ & $0.006 *$ & (0.003) \\
\hline LIFE & $0.036 * *$ & $(0.018)$ & $0.033 *$ & $(0.018)$ \\
\hline HHSIZE & 0.007 & $(0.005)$ & 0.003 & $(0.006)$ \\
\hline PROTECT & 0.029 & $(0.030)$ & 0.037 & (0.029) \\
\hline VISITED NTB ${ }^{b}$ & 0.011 & $(0.021)$ & 0.009 & $(0.020)$ \\
\hline Observations & 2,110 & & 2,110 & \\
\hline Groups & 422 & & 422 & \\
\hline$R^{2}$ & 0.073 & & 0.075 & \\
\hline
\end{tabular}

Notes: We use robust standard errors.

a Dummy variable indicating agreement with the statement "The marine environment needs to be better protected"

b Dummy variable indicating whether a respondent has visited the islands in Nha Trang Bay 